Chapman University

Chapman University Digital Commons

Mathematics, Physics, and Computer Science

Science and Technology Faculty Articles and

Faculty Articles and Research

Research

2010

\title{
Estimation of Effective Plant Area Index for South Korean Forests Using LiDAR System
}

D. A. Kwak

Korea University

W. K. Lee

Korea Univ

Menas Kafatos

Chapman University, kafatos@chapman.edu

Y.Son

Korea University

H. K. Cho

Korea Forest Research Institute

See next page for additional authors

Follow this and additional works at: http://digitalcommons.chapman.edu/scs_articles

Part of the Forest Sciences Commons, and the Plant Sciences Commons

\section{Recommended Citation}

Kwak, D.A., Lee, W.K., Kafatos, M., Son, Y., Cho, H.K., Lee, S.H. (2010) Estimation of effective plant area index for South Korean forests using LiDAR system, Science China, Life Sciences Vol. 53, No. 7: 898-908, doi: 10.1007/s11427-010-4019-z

This Article is brought to you for free and open access by the Science and Technology Faculty Articles and Research at Chapman University Digital Commons. It has been accepted for inclusion in Mathematics, Physics, and Computer Science Faculty Articles and Research by an authorized administrator of Chapman University Digital Commons. For more information, please contact laughtin@chapman.edu. 


\section{Estimation of Effective Plant Area Index for South Korean Forests Using LiDAR System}

\section{Comments}

This article was originally published in Science China, Life Sciences, volume 53, issue 7, in 2010. DOI: 10.1007/ s11427-010-4019-z

\section{Creative Commons License}

\section{(c) (i)}

This work is licensed under a Creative Commons Attribution 3.0 License.

\section{Authors}

D. A. Kwak, W. K. Lee, Menas Kafatos, Y. Son, H. K. Cho, and S. H. Lee 


\title{
Estimation of effective plant area index for South Korean forests using LiDAR system
}

\author{
KWAK Doo-Ahn ${ }^{1}$, LEE Woo-Kyun ${ }^{1 *}$, KAFATOS Menas ${ }^{2}$, SON Yowhan ${ }^{1}$, \\ CHO Hyun-Kook ${ }^{3} \&$ LEE Seung-Ho ${ }^{3}$ \\ ${ }^{1}$ Department of Environmental Science and Ecological Engineering, Korea University, Seoul 136-713, Korea; \\ ${ }^{2}$ Center of Excellence in Earth Observing, Schmid College of Science, Chapman University, Orange, CA 92866, USA; \\ ${ }^{3}$ Division of Forest Resources Information, Korea Forest Research Institute, Seoul 136-012, Korea
}

Received February 9, 2010; accepted April 3, 2010

\begin{abstract}
Light Detection and Ranging (LiDAR) systems can be used to estimate both vertical and horizontal forest structure. Woody components, the leaves of trees and the understory can be described with high precision, using geo-registered 3D-points. Based on this concept, the Effective Plant Area Indices $\left(\mathrm{PAI}_{\mathrm{e}}\right.$ ) for areas of Korean Pine (Pinus koraiensis), Japanese Larch (Larix leptolepis) and Oak (Quercus spp.) were estimated by calculating the ratio of intercepted and incident LIDAR laser rays for the canopies of the three forest types. Initially, the canopy gap fraction $\left(G_{L i D A R}\right)$ was generated by extracting the LiDAR data reflected from the canopy surface, or inner canopy area, using $k$-means statistics. The LiDAR-derived PAI $\mathrm{e}_{\mathrm{e}}$ was then estimated by using $G_{L I D A R}$ with the Beer-Lambert law. A comparison of the LiDAR-derived and field-derived PAI $_{\mathrm{e}}$ revealed the coefficients of determination for Korean Pine, Japanese Larch and Oak to be $0.82,0.64$ and 0.59 , respectively. These differences between field-based and LIDAR-based $\mathrm{PAI}_{\mathrm{e}}$ for the different forest types were attributed to the amount of leaves and branches in the forest stands. The absence of leaves, in the case of both Larch and Oak, meant that the LiDAR pulses were only reflected from branches. The probability that the LiDAR pulses are reflected from bare branches is low as compared to the reflection from branches with a high leaf density. This is because the size of the branch is smaller than the resolution across and along the 1 meter LIDAR laser track. Therefore, a better predictive accuracy would be expected for the model if the study would be repeated in late spring when the shoots and leaves of the deciduous trees begin to appear.
\end{abstract}

leaf area index, plant area index, LiDAR, k-means clustering, gap fraction, beer-lambert law

Citation: Kwak D A, Lee W K, Kafatos M, et al. Estimation of effective plant area index for South Korean forests using LiDAR system. Sci China Life Sci, 2010, 53: 898-908, doi: 10.1007/s11427-010-4019-z

The amount of leaves present in a forest canopy is generally expressed as the leaf area index (LAI) which is defined as the total one-sided area of leaf tissue per unit ground surface area [1]. A tree's leaf area has direct influence upon its levels of evaporation, water interception, radiation extinction and water-carbon gas exchange [1]. Due to such LAI effects upon numerous relevant ecological processes, of hydrology (capture, storage, and redistribution of precipitation), energy

*Corresponding author (email: leewk@korea.ac.kr) capture (conversion of sunlight to plant and animal matter), and nutrient cycling (cycle of nutrients through the physical and biotic components of the environment), LAI estimates can provide information useful for various models [2-5].

Methods for obtaining the LAI can be classified into two categories: direct and indirect measurements [6]. Direct methods are destructive due to the need to harvest vegetation and are usually both time-consuming and laborintensive. Therefore, direct methods are more suitable for small plots containing smaller structural vegetation types 
and are difficult to apply to large areas or to tree canopies [6-7]. The LAI can also be obtained using an indirect and non-destructive method, through estimation using transmission and reflection characteristics of sunlight through vegetation areas [8-9].

Previously, to derive such LAI estimates, remote sensing techniques, such as satellite imagery and aerial photography, have been employed. Such approaches are based on regression models [10] or radiative transfer modeling [11] using passive optical sensor systems. However, passive remote sensor systems cannot describe the 3D structure of leaf distribution with a single scene. Furthermore, they employ indexes of spectral characteristics, such as the Normalized Difference Vegetation Index (NDVI), which are derived from satellite imagery and aerial photography, and which fail to distinguish between woody components and leaves [12-15].

More recently Light Detection and Ranging (LiDAR) has been used to extract surface information, and can acquire accurate object shape characteristics using geo-registered 3-dimensional $(x, y, z)$ mass points [16]. Therefore, the LiDAR system can measure both vertical and horizontal forest structural parameters with high precision. Such parameters can include tree height, sub-canopy morphology and leaf distribution [17]. Morsdorf et al. [18] derived the LAI using fractional cover, defined as the fraction of ground covered by vegetation over uncovered ground. Riaño et al. [19] obtained the LAI using the gap fraction, referring to the probability that the LIDAR beam will have no contact with vegetation elements prior to reaching ground level [20]. Lovell et al. [21] employed a ground-based laser scanner in Australian forests to model the LAI using a canopy profile. Koetz et al. [22] applied a LiDAR waveform model to generate fractional cover and the LAI from small footprint LiDAR data, but only for large footprint sensors. The small footprint LiDAR system can record discrete returns but not the entire waveform. These discrete returns provide an opportunity to extract valuable biophysical parameters of individual trees because of their high spatial resolution [23]. However, the large footprint LiDAR system cannot provide this information due to its larger footprint size and coarse spacing [24]. The use of ground based laser scanners is limited by the topographical conditions of the forest area (precluding inaccessible places, such as steep slopes and valley forest areas). Moreover, it is impossible to simultaneously scan a large forest area using a ground based laser scanner. This becomes feasible when using an airbornebased small footprint LiDAR system.

A common field method for determining the LAI is to use an optical sensor, such an AccuPAR-80 (Linear PAR/ LAI Ceptometer of Decagon Devices), or a LAI-2000 (LICOR Biosciences), to acquire photosynthetically active radiation (PAR), or to use hemispherical photography below the canopy [25]. However, the values recorded by these instruments are not pure LAIs because they tend to clump the varied aspects of canopy components and lack the capacity to be adjusted to incorporate the influence of woody components [25]. The value recorded without the consideration of the clumping of canopy components is defined as the Effective LAI $\left(\mathrm{LAI}_{e}\right)$ [20]. Methods that do not consider the difference in light interception between the leaves and woody components determine the so-called the Plant Area Index (PAI) [26]. The amount of plant matter is commonly quantified in terms of the PAI, expressed as square meter of plant area per square meter of ground area [27]. The PAI values measured by these instruments are likewise referred to as the Effective PAI $\left(\mathrm{PAI}_{\mathrm{e}}\right)$ if there are no adjustments for the clumping of canopy elements [15]. Therefore, the values measured with optical sensors in the forest areas essentially represent the $\mathrm{PAI}_{\mathrm{e}}[25]$.

In this study, a $\mathrm{PAI}_{\mathrm{e}}$ estimation was used for a forested area of South Korea. Chen et al. [28] reported that a $\mathrm{PAI}_{\mathrm{e}}$ estimation was more effective than a LAI estimation because the $\mathrm{PAI}_{\mathrm{e}}$ also represents the sunlight interception by woody elements. In particular, the LiDAR pulses were reflected on all tree components including leaves, branches and stems. Therefore, in this study, the $\mathrm{PAI}_{\mathrm{e}} \mathrm{s}$ of the Korean Pine (Pinus koraiensis), Japanese Larch (Larix leptolepis) and Oak (Quercus spp.) were estimated. To do this, the rate of in-canopy returns, as LiDAR pulses intercepted through the canopy, were calculated. Furthermore, an attempt was made to estimate the $\mathrm{PAI}_{\mathrm{e}}$ for the leaf canopy part alone by splitting the classification of LiDAR pulses reflected in the forest stands into in-canopy and below-canopy returns by using $k$-means statistics.

\section{Materials}

\subsection{Study area}

There were two study areas in central South Korea (Figure $1)$. The first is Mt. Yumyeong $\left(127^{\circ} 28^{\prime} 45.76074^{\prime \prime} \mathrm{E}, 37^{\circ} 35^{\prime}\right.$ $59.75109^{\prime \prime} \mathrm{N}$ to $\left.127^{\circ} 30^{\prime} 6.98627^{\prime \prime} \mathrm{E}, 37^{\circ} 35^{\prime} 6.27425^{\prime \prime} \mathrm{N}\right)$, and the second is located in the Gwangneung Experimental Forest of the Korea Forest Research Institute $\left(127^{\circ} 7^{\prime} 30.72523^{\prime \prime} \mathrm{E}\right.$, $37^{\circ} 48^{\prime} 0.42761^{\prime \prime} \mathrm{N}$ to $\left.127^{\circ} 11^{\prime} 59.17548^{\prime \prime} \mathrm{E}, 37^{\circ} 41^{\prime} 59.31795^{\prime \prime} \mathrm{N}\right)$. Elevations ranged from 160 to $573 \mathrm{~m}$ above sea level and the study areas were dominated by steep hills with the main forest type being Korean Pine (Pinus koraiensis), Japanese Larch (Larix leptolepis) and Oak (Quercus spp.). Approximately 1,017 ha were selected for this study where the composition of tree species was homogeneous but the edges of the individual tree crowns overlapped with the neighboring trees due to the high tree density.

\subsection{LiDAR and ground data}

An Optech ALTM 3070 (a small footprint LiDAR system) was used to acquire the LiDAR data. The flight was performed on the 3rd of April 2007 at an altitude of $1400 \mathrm{~m}$ with a sampling density of 5-10 points per square meter, 
and a radiometric resolution, scan frequency, scan width and beam divergence of 12 bits, $70 \mathrm{~Hz}, \pm 20^{\circ}$ and $0.31 \mathrm{mrad}$, respectively.

The field survey was performed from the 1 st to the 4 th of April, 2008. The number of sample plots was 45 (15 plots for each forest type: Korean Pine, Japanese Larch and Oak). There were also 45 test plots. The stand height, diameter at breast height $(\mathrm{DBH})$, crown base height, crown width and tree density were measured (Table 1).

Each plot was $20 \mathrm{~m} \times 20 \mathrm{~m}\left(400 \mathrm{~m}^{2}\right)$ in size, and the $\mathrm{PAI}_{\mathrm{e}}$ of the plots was measured indirectly using the gap fraction method with two LAI-2000 instruments that recorded the diffuse radiation intensity above and below the canopy. One LAI-2000, used to measure the diffuse sunlight above the canopy, was covered with a $180^{\circ}$ view cap and placed on the flux tower located in the forest. The other LAI-2000, also covered with a $180^{\circ}$ view cap, was used to measure the diffused sunlight below the canopy of the sample plots. The estimation below the canopy was performed at breast height on the midpoints of the four edge lines as well as on the four corners of the plots. In addition, the $\mathrm{PAI}_{\mathrm{e}} \mathrm{s}$ were measured in four directions (East, West, South, and North) from the centre of each plot (Figure 2). The $\mathrm{PAI}_{\mathrm{e}} \mathrm{s}$ for the four corners were also obtained in the $180^{\circ}$ range. These were then converted into corresponding values in the $90^{\circ}$ range using the LAI-2000 File Viewer Program to exclude the values outside of the sample plot. The coordinates of the plots were acquired at breast height at the centre of each plot using a GPS Pathfinder Pro XR (Trimble Corporation). As only a single GPS receiver was used for positioning, positional errors in the plots were avoided by, processing the GPS data in reference to the signal from a continuous GPS signal station near the study area. Differential correc- tions could be performed using the error-correction information received from the station to acquire precise position and error correction information every 30 seconds [29]. The final positions of the correctly geo-referenced plots were obtained with a positional accuracy of within $1 \mathrm{~m}$.

\section{Method}

\subsection{Potential of LiDAR remote sensing for PAIe esti- mation}

The laser pulses emitted from the LiDAR system act in a similar manner to sunlight in that they are reflected from or transmitted through the canopy of the forested area. The measurement is suitable for representing the $\mathrm{PAI}_{\mathrm{e}}$ rather than the LAI because the LiDAR pulses are reflected from all tree elements, including leaves, branches and stems. If the forest stands have abundant leaves and branches, the LiDAR pulses are reflected mainly by the canopy. Otherwise, in bare-branched forest stands, the LiDAR pulses are almost all transmitted to the ground with the exception of those reflected from the woody elements.

The Beer-Lambert Law has been used to estimate the $\mathrm{PAI}_{\mathrm{e}}$ in many studies [25]:

$$
P A I_{e}=-\ln \left(I / I_{0}\right) / k_{\text {sun }},
$$

where $I$ and $I_{0}$ are the incident radiation and below-canopy radiation, respectively, and $k_{\text {sun }}$ is the extinction coefficient for solar radiation. In equation $1, I / I_{0}$ denotes the gap fraction $\left(G_{\text {sun }}\right)$, which is defined as the probability of an incident light ray passing through the canopy without colliding with any canopy or woody element [30]. The $G_{\text {sun }}$ of solar radiation can be replaced with the ratio of the number of LiDAR returns transmitted through the canopy to the total number

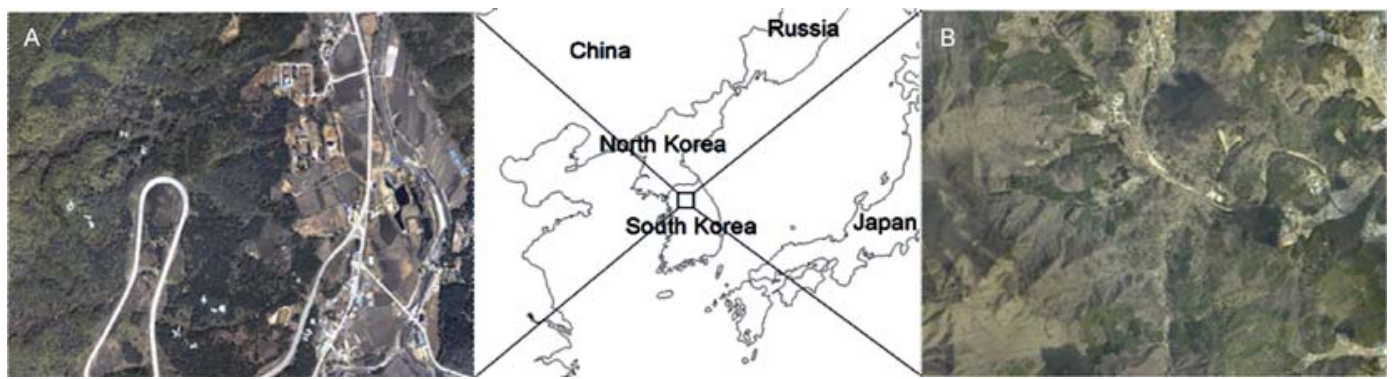

Figure 1 Digital aerial photographs of the study area acquired on the 3rd of April 2007. A, Mt. Yumyeong; B, Gwangneung experimental forest.

Table 1 Descriptive statistics of the field measurements

\begin{tabular}{|c|c|c|c|c|c|c|c|c|c|}
\hline & \multicolumn{2}{|c|}{ Tree height (m) } & \multicolumn{2}{|c|}{ Crown base height $(\mathrm{m})$} & \multicolumn{2}{|c|}{$\mathrm{DBH}(\mathrm{cm})$} & \multicolumn{2}{|c|}{ Crown width (m) } & \multirow{2}{*}{$\begin{array}{l}\text { Tree density } \\
\qquad\left(\mathrm{N} \mathrm{ha}^{-1}\right)\end{array}$} \\
\hline & Mean & Std. & Mean & Std. & Mean & Std. & Mean & Std. & \\
\hline Korean Pine & 20.7 & 3.9 & 14.4 & 3.1 & 32.7 & 5.5 & 5.3 & 1.1 & 375 \\
\hline Japanese Larch & 27.8 & 2.3 & 16.1 & 2.0 & 28.7 & 4.6 & 6.5 & 1.3 & 300 \\
\hline Oaks & 20.0 & 2.7 & 11.1 & 1.6 & 28.3 & 8.9 & 7.8 & 2.4 & 200 \\
\hline
\end{tabular}




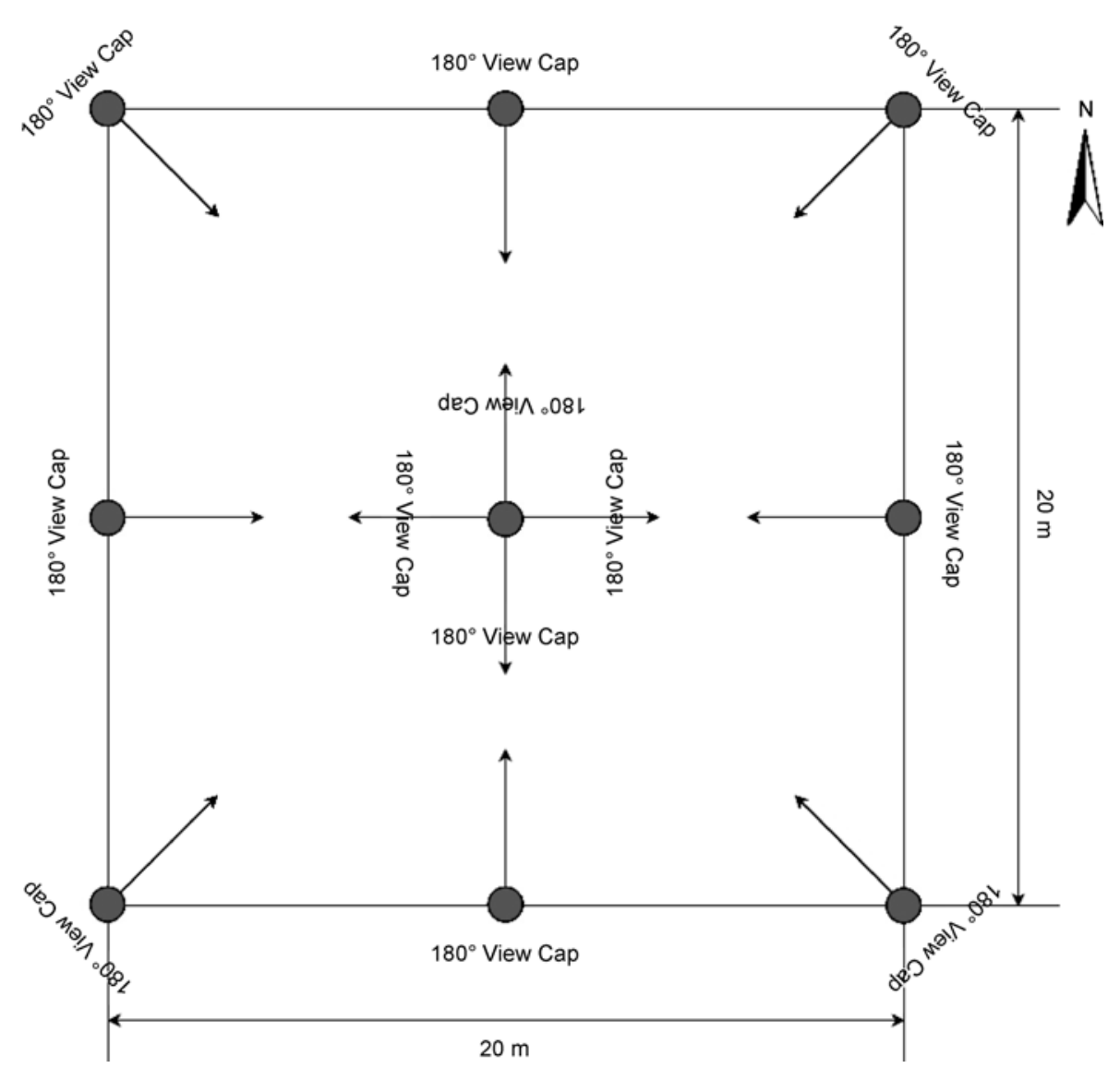

Figure 2 Schematic diagram of the method for estimating effective plant area indices in a plot. Each arrow represents the direction. In all cases sensors were restricted with a $180^{\circ}$ view cap.

of LiDAR returns emitted from the aircraft $\left(G_{L i D A R}\right) . k_{s u n}$ in equation 1 can be calculated using equation 2 [31].

$$
k_{\text {sun }}=\frac{\left(x^{2}+\tan ^{2} \theta_{\text {sun }}\right)^{\frac{1}{2}}}{x+1.744(x+1.182)^{-0.733}},
$$

where $\theta_{\text {sun }}$ is the zenith angle of the sun and $x$ is the leaf angle distribution parameter, which is the ratio of the length of the horizontal to vertical axis of the spheroid, and can be measured as the ratio of the projected area of an average canopy element onto a horizontal plane to its projection onto a vertical plane [31]. Campbell [31] suggested that the assumption of an ellipsoidal angle distribution for canopy elements would be most useful. Using this assumption, $k_{\text {sun }}$ can then be simplified to:

$$
k_{\text {sun }}=\frac{1}{2 \cos \theta_{\text {sun }}} .
$$

In equation $3, k_{\text {sun }}$ could be calculated using the solar zenith angle $\left(\theta_{\text {sun }}\right)$ for the study area. However, to apply to the $\mathrm{PAI}_{\mathrm{e}}$ obtained from LiDAR data, the $\theta_{\text {sun }}$ in the above equation must be changed to the incidence angle of the laser pulses emitted from the aircraft $\left(\theta_{L i D A R}\right)$. In the plot or stand level estimation, the LAI or PAI cannot be represented independently from each pulse reflected within a target plot.
All returns reflected within a plot must be collectively integrated to obtain a plot-level LAI or PAI. However, each return has a different incidence angle because each point is generated by a flight line with a unique scan angle when emitted from a whiskbroom laser scanner. Therefore, LiDAR-derived $\mathrm{PAI}_{\mathrm{e}}$ was analyzed using the mean value of the incidence angle of all returns within a plot.

\subsection{Classification of the LiDAR data using $k$-means statistic}

To calculate $G_{L i D A R}$, the transmitted laser pulses need to be collected and classified together as total laser returns. In particular, the LiDAR returns intercepted only by the canopy must be clustered in order to estimate the canopy $\mathrm{PAI}_{\mathrm{e}}$ under the same conditions as sunlight transmission through the canopy. Riaño et al. [19] tested a variety of clustering methods to classify their LiDAR data. These included a $3 \mathrm{~m}$ fixed limit, Minimum Euclidean Distance clustering, $k$-means clustering and Expectation Maximization clustering. In this study, the $k$-means algorithm was used because it was the fastest method that consistently worked well at the plot level for splitting the classification of the LiDAR returns into those of in-canopy and below-canopy [19]. For classification, the criterion height dividing in-canopy and 
below-canopy can be determined to be the crown base height at the plot level. This is because the crown represents the branching, leaf-bearing portion of a tree occurring above the crown base height [32].

The $k$-means statistic is an algorithm used to classify or group attributes or features into $k$ numbers of groups. It employs an iterative algorithm that minimizes the sum of the distances (SOD) from each object ( $n$ ) to its cluster centroid (i) over all clusters (Equation 4).

$$
S O D_{i \ldots j}=\sum_{i}^{j} \mid \text { Centroid }_{i \ldots j}-\text { Object }[n] \mid .
$$

This algorithm moves objects between clusters until the sum cannot be decreased further. This results in a set of clusters that are as compact and separated as possible [33]. The LiDAR returns reflected within a plot were classified into five $Z$ values (height values). These were the ground, understory height, crown base height, half crown height and tree height groups. The mean height of the points (Mean LH and Mean LiDAR Height) in the crown base height group was used to represent the crown base height of a plot (Figure 3).

In general, the initial points of each cluster can be selected by the user when the $k$-means algorithm is performed [33]. In this study, the initial point values for the clusters were derived from the field inventory. The arithmetic process was performed with 100 iterations. The cluster was treated as being undefined if it was too small. An example would be where the percentage of laser pulses of a group had $<1 /$ (total number of clusters) ${ }^{2}$ [19]. The extracted crown base height was used as the criterion to partition the in-canopy and below-canopy returns within a plot.

\subsection{Generation of LiDAR-derived gap fraction}

Barilotti et al. [34] suggested the use of the laser penetration index (LPI), which is the ratio of the ground and vegetation returns in the sample plots. All the LiDAR points were divided into two classes of vegetation returns: high (height $\geqslant 1$ $\mathrm{m}$ above ground) and low (height $<1 \mathrm{~m}$ above ground). However, in the case of multiple understories, the LPI was inflexible because the value used to distinguish between the ground and high vegetation returns was fixed at a height of $1 \mathrm{~m}$ above the ground regardless of the characteristics of the forest stand. However, this study determined the threshold value (mean laser height of the crown base height group) using a statistical criterion by $k$-means clustering. The mean crown base height of a plot could be extracted using the threshold value and then the below-canopy and in-canopy returns were classified. The LiDAR-derived gap fraction was generated from:

$$
G_{\text {LiDAR }}=\frac{N_{\text {below- canopy returns }}}{N_{\text {all returns }}},
$$

where $N_{\text {below-canopy returns }}$ is the number of LiDAR returns re- flected below the canopy and $N_{\text {all returns }}$ is the whole number of LiDAR returns reflected in a sample plot.

According to Equation 5, the vegetation is dense if the $G_{L I D A R}$ value is close to 0 but sparse if the value is close to 1 . Thus, the $\mathrm{PAI}_{\mathrm{e}}$ can be estimated artificially by substituting

A

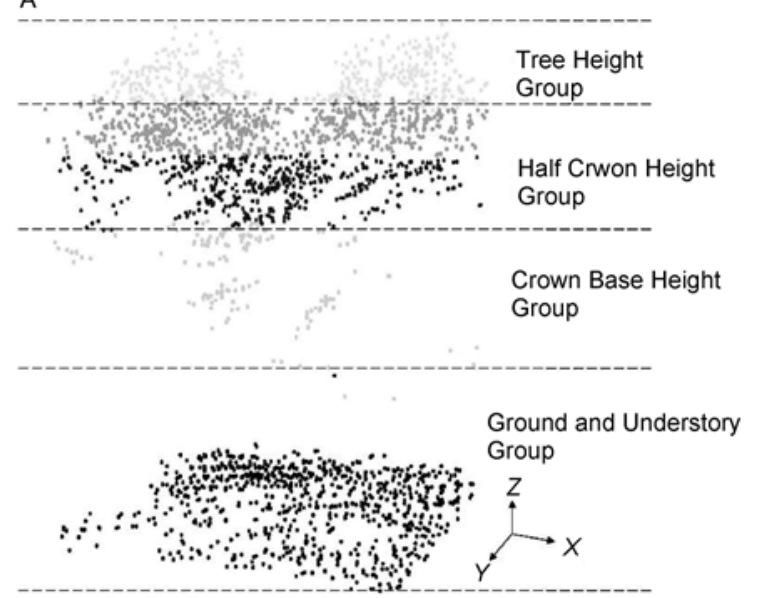

B
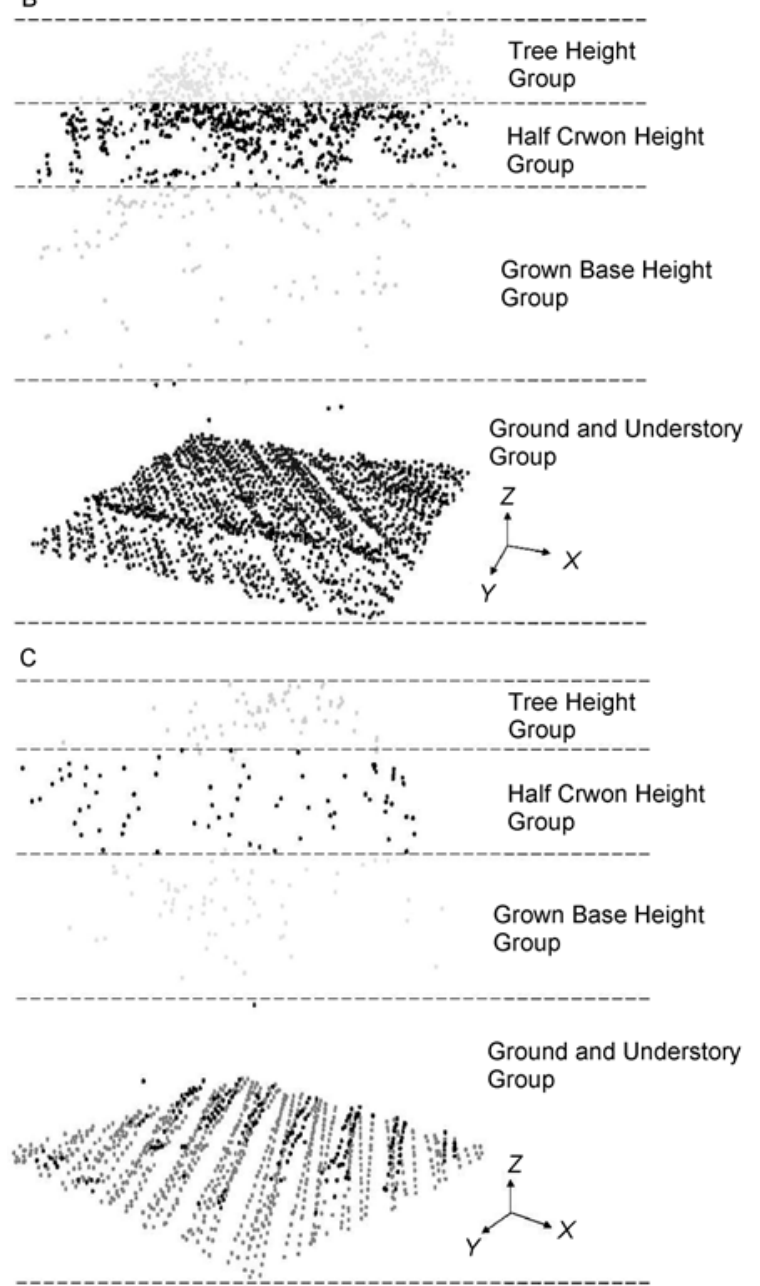

Figure 3 Classification of the LiDAR returns into five clusters by $k$ means clustering. A, Pinus koraiensis; B, Larix leptolepis; C, Quercus spp. 
$G_{\text {sun }}$ and $k_{\text {sun }}$ by $G_{L i D A R}$ and $k_{L i D A R}$, respectively:

$$
P A I_{e}=-2 \cos \theta_{L i D A R} \ln G_{L i D A R} \text {. }
$$

\section{Results}

\subsection{Classification of the LiDAR data}

The LiDAR returns were classified using $k$-means clustering. Returns by forest type were classified into two clusters according to the LiDAR-derived crown base heights (Figure 4). Results show the typical distribution of the LiDAR returns according to the forest type.

The plots of Korean Pine displayed an abundant monolayer canopy. LiDAR returns for the pines were therefore clustered clearly into two groups. However, some of the LiDAR pulses in the plots for Japanese Larch and Oak suggested in-between layers due to the presence of various understories. The results of $k$-means clustering were acceptable because the LiDAR-derived crown base heights, extracted from the mean $\mathrm{LH}$, were similar to the actual field-derived crown base heights. These $k$-means clustering results were used to estimate the LiDAR-derived $\mathrm{PAI}_{\mathrm{e}}$ using $G_{\text {LiDAR }}$ (Table 2).

Linear regression analysis was carried out to determine the relationship between the LiDAR-derived and field- derived crown base heights. The coefficient of determination $\left(R^{2}\right)$ and root mean square error (RMSE) were calculated to assess the accuracy of regression analysis (Table 3 ).

\subsection{Estimation of effective plant area index using Li- DAR gap fraction}

Using the $G_{L I D A R}$ and $\theta_{L I D A R}$ values, the LiDAR-derived PAI was estimated for the different forest types. The $\mathrm{PAI}_{\mathrm{e}}$ values for the Korean Pine were higher than those for the Japanese Larch and Oak because the Korean Pine is an evergreen needle-leaved tree having dense leaves. On the other hand, the $\mathrm{PAI}_{\mathrm{e}}$ values of Japanese Larch and Oak were relatively low because they had very few leaves present on their branches at the time the field survey was carried out, (1st to 4 th of April). However, the $\mathrm{PAI}_{\mathrm{e}}$ values of Japanese Larch were somewhat higher than those of Oak due to the emitted LiDAR pulses being more reflected from the denser branches of Japanese Larch than from the less dense branching of the Oaks (Figure 5B).

Linear regression analysis was carried out to determine the relationship between the LiDAR-derived and fieldderived $\mathrm{PAI}_{\mathrm{e}}$. The coefficient of determination and root mean square errors were calculated to determine the accuracy of regression analysis (Table 3 ).

The correlation for Korean Pine $\left(R^{2}=0.66\right)$ was the high-
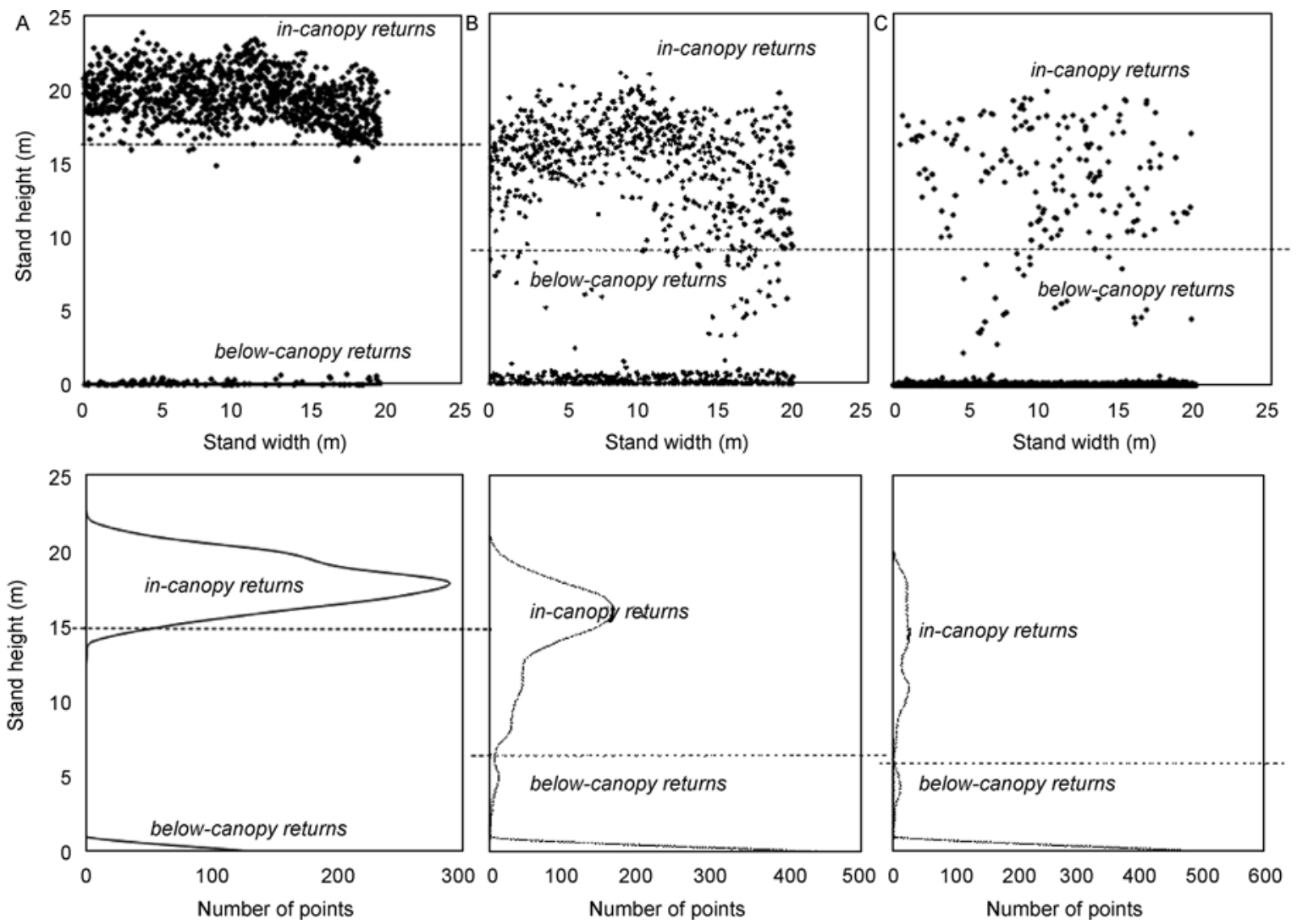

Figure 4 Distribution of the LiDAR returns of the three forest types and classification into two clusters for each (in-canopy and below-canopy returns). A, Korea pine; B, Japanese larch; C, oaks. 
Table 2 Results of LiDAR-derived estimators and comparison of field- and LiDAR-derived estimations for each sample plot

\begin{tabular}{|c|c|c|c|c|c|c|c|c|}
\hline Forest type & Plot No. & $\begin{array}{c}\text { Mean LH } \\
(\mathrm{m})\end{array}$ & $G_{L i D A R}$ & $\begin{array}{c}\text { Mean } \\
\theta_{\text {LiDAR }}\left({ }^{\circ}\right) \\
\end{array}$ & $\begin{array}{c}\text { Field-derived } \\
\mathrm{CBH}(\mathrm{m})\end{array}$ & $\begin{array}{c}\text { LiDAR-derived } \\
\text { CBH }(\mathrm{m})\end{array}$ & $\begin{array}{c}\text { Field-derived } \\
\mathrm{PAI}_{\mathrm{e}} \\
\end{array}$ & $\begin{array}{c}\text { LiDAR-derived } \\
\text { PAI }_{e}\end{array}$ \\
\hline \multirow{15}{*}{ Korean Pine } & 1 & 19.32 & 0.12 & 12.47 & 16.47 & 18.17 & 3.33 & 4.17 \\
\hline & 2 & 18.06 & 0.16 & 11.44 & 17.07 & 17.11 & 3.93 & 3.59 \\
\hline & 3 & 20.14 & 0.22 & 12.06 & 17.87 & 18.86 & 3.33 & 2.96 \\
\hline & 4 & 16.67 & 0.58 & 11.77 & 15.30 & 15.95 & 2.58 & 1.08 \\
\hline & 5 & 16.41 & 0.23 & 12.49 & 15.77 & 15.72 & 3.30 & 2.86 \\
\hline & 6 & 20.07 & 0.69 & 11.73 & 20.80 & 18.80 & 2.66 & 0.74 \\
\hline & 7 & 13.25 & 0.31 & 13.66 & 14.03 & 13.07 & 3.38 & 2.25 \\
\hline & 8 & 13.87 & 0.37 & 15.01 & 13.53 & 13.59 & 3.17 & 1.90 \\
\hline & 9 & 10.06 & 0.24 & 9.79 & 10.73 & 10.39 & 3.41 & 2.79 \\
\hline & 10 & 11.40 & 0.22 & 11.25 & 11.50 & 11.51 & 3.55 & 3.00 \\
\hline & 11 & 10.06 & 0.21 & 14.88 & 9.20 & 10.39 & 3.86 & 2.97 \\
\hline & 12 & 10.42 & 0.20 & 12.22 & 10.60 & 10.69 & 3.75 & 3.11 \\
\hline & 13 & 15.38 & 0.13 & 11.89 & 15.17 & 14.86 & 3.90 & 4.05 \\
\hline & 14 & 15.30 & 0.13 & 11.92 & 15.90 & 14.79 & 3.75 & 4.04 \\
\hline & 15 & 12.96 & 0.06 & 12.28 & 12.80 & 12.83 & 3.90 & 5.66 \\
\hline \multirow{15}{*}{$\begin{array}{l}\text { Japanese } \\
\text { Larch }\end{array}$} & 1 & 14.41 & 0.83 & 12.85 & 16.80 & 14.47 & 1.23 & 0.36 \\
\hline & 2 & 17.02 & 0.89 & 12.76 & 16.07 & 16.53 & 1.38 & 0.22 \\
\hline & 3 & 17.20 & 0.89 & 13.93 & 16.20 & 16.68 & 1.38 & 0.24 \\
\hline & 4 & 15.63 & 0.74 & 12.89 & 16.83 & 15.44 & 1.63 & 0.57 \\
\hline & 5 & 16.80 & 0.80 & 13.79 & 15.20 & 16.36 & 1.56 & 0.44 \\
\hline & 6 & 18.70 & 0.90 & 13.29 & 17.87 & 17.86 & 1.46 & 0.20 \\
\hline & 7 & 17.58 & 0.85 & 13.24 & 17.93 & 16.98 & 1.63 & 0.32 \\
\hline & 8 & 15.90 & 0.85 & 13.83 & 16.43 & 15.65 & 1.51 & 0.32 \\
\hline & 9 & 17.16 & 0.88 & 12.43 & 16.13 & 16.64 & 1.48 & 0.25 \\
\hline & 10 & 14.71 & 0.70 & 11.47 & 15.27 & 14.71 & 1.60 & 0.69 \\
\hline & 11 & 18.94 & 0.69 & 12.29 & 18.57 & 18.05 & 1.70 & 0.73 \\
\hline & 12 & 17.70 & 0.83 & 6.13 & 15.53 & 17.07 & 1.46 & 0.38 \\
\hline & 13 & 11.00 & 0.86 & 11.72 & 10.17 & 11.78 & 1.33 & 0.30 \\
\hline & 14 & 15.03 & 0.92 & 14.96 & 14.57 & 14.96 & 1.11 & 0.16 \\
\hline & 15 & 19.41 & 0.68 & 12.64 & 18.03 & 18.42 & 1.77 & 0.74 \\
\hline \multirow{15}{*}{ Oaks } & 1 & 14.71 & 0.97 & 12.27 & 14.70 & 13.55 & 1.26 & 0.06 \\
\hline & 2 & 8.74 & 0.94 & 9.84 & 9.47 & 9.82 & 1.24 & 0.12 \\
\hline & 3 & 11.19 & 0.95 & 13.52 & 10.73 & 11.35 & 1.33 & 0.10 \\
\hline & 4 & 8.58 & 0.94 & 13.12 & 10.77 & 9.73 & 1.29 & 0.11 \\
\hline & 5 & 10.65 & 0.95 & 9.75 & 12.07 & 11.02 & 1.24 & 0.10 \\
\hline & 6 & 12.23 & 0.97 & 13.27 & 11.17 & 12.00 & 1.13 & 0.06 \\
\hline & 7 & 11.92 & 0.93 & 13.21 & 12.83 & 11.81 & 1.34 & 0.15 \\
\hline & 8 & 7.20 & 0.98 & 13.48 & 9.77 & 8.86 & 1.25 & 0.05 \\
\hline & 9 & 11.07 & 0.95 & 12.83 & 12.47 & 11.28 & 1.32 & 0.11 \\
\hline & 10 & 12.92 & 0.97 & 13.02 & 12.00 & 12.44 & 1.24 & 0.06 \\
\hline & 11 & 11.31 & 0.97 & 8.90 & 10.10 & 11.43 & 1.15 & 0.05 \\
\hline & 12 & 11.34 & 0.98 & 8.84 & 10.60 & 11.45 & 1.2 & 0.05 \\
\hline & 13 & 12.39 & 0.96 & 9.17 & 11.57 & 12.10 & 1.26 & 0.09 \\
\hline & 14 & 8.72 & 0.93 & 6.29 & 9.17 & 9.81 & 1.3 & 0.15 \\
\hline & 15 & 8.09 & 0.98 & 7.54 & 8.67 & 9.42 & 1.12 & 0.04 \\
\hline
\end{tabular}


Table 3 Accuracy of the regression function generated for the crown base height and effective plant area index

\begin{tabular}{|c|c|c|c|c|c|c|c|}
\hline Forest type & Equation & $R^{2}$ & RMSE & Coefficient & Estimate & $t$-statistics & $P$-value \\
\hline \multirow[t]{4}{*}{ Korean Pine } & $C B H=\alpha_{1} \cdot$ Mean $L H+\beta_{1}$ & 0.91 & 0.81 & $\alpha_{1}$ & 0.8405 & 11.5846 & $3.1850 \times 10^{-8}$ \\
\hline & & & & $\beta_{1}$ & 1.9315 & 1.7358 & 0.1062 \\
\hline & $P A I_{e}=\alpha_{2} \cdot \cos \theta_{L i D A R} \cdot \ln G_{L i D A R}+\beta_{2}$ & 0.66 & 1.00 & $\alpha_{2}$ & -0.5544 & -5.2717 & 0.0001 \\
\hline & & & & $\beta_{2}$ & 2.6615 & 14.6842 & $1.7943 \times 10^{-9}$ \\
\hline \multirow[t]{4}{*}{ Japanese Larch } & $C B H=\alpha_{1} \cdot$ Mean $L H+\beta_{1}$ & 0.70 & 1.12 & $a_{1}$ & 0.7893 & 5.5650 & $9.1497 \times 10^{-5}$ \\
\hline & & & & $\beta_{1}$ & 3.0998 & 1.3186 & 0.2100 \\
\hline & $P A I_{e}=\alpha_{2} \cdot \cos \theta_{L i D A R} \cdot \ln G_{L i D A R}+\beta_{2}$ & 0.58 & 1.12 & $\alpha_{2}$ & -1.3736 & -4.2097 & 0.0010 \\
\hline & & & & $\beta_{2}$ & 1.2103 & 17.2439 & $2.4447 \times 10^{-10}$ \\
\hline \multirow[t]{3}{*}{ Oaks } & $C B H=\alpha_{1} \cdot$ Mean $L H+\beta_{1}$ & 0.66 & 0.79 & $\alpha_{1}$ & 0.6249 & 5.0476 & 0.0002 \\
\hline & & & & $\beta_{1}$ & 4.3622 & 3.2413 & 0.0064 \\
\hline & $P A I_{e}=\alpha_{2} \cdot \cos \theta_{L i D A R} \cdot \ln G_{L i D A R}+\beta_{2}$ & 0.51 & 1.34 & $\alpha_{2}$ & -2.6978 & -3.4931 & 0.0040 \\
\hline
\end{tabular}
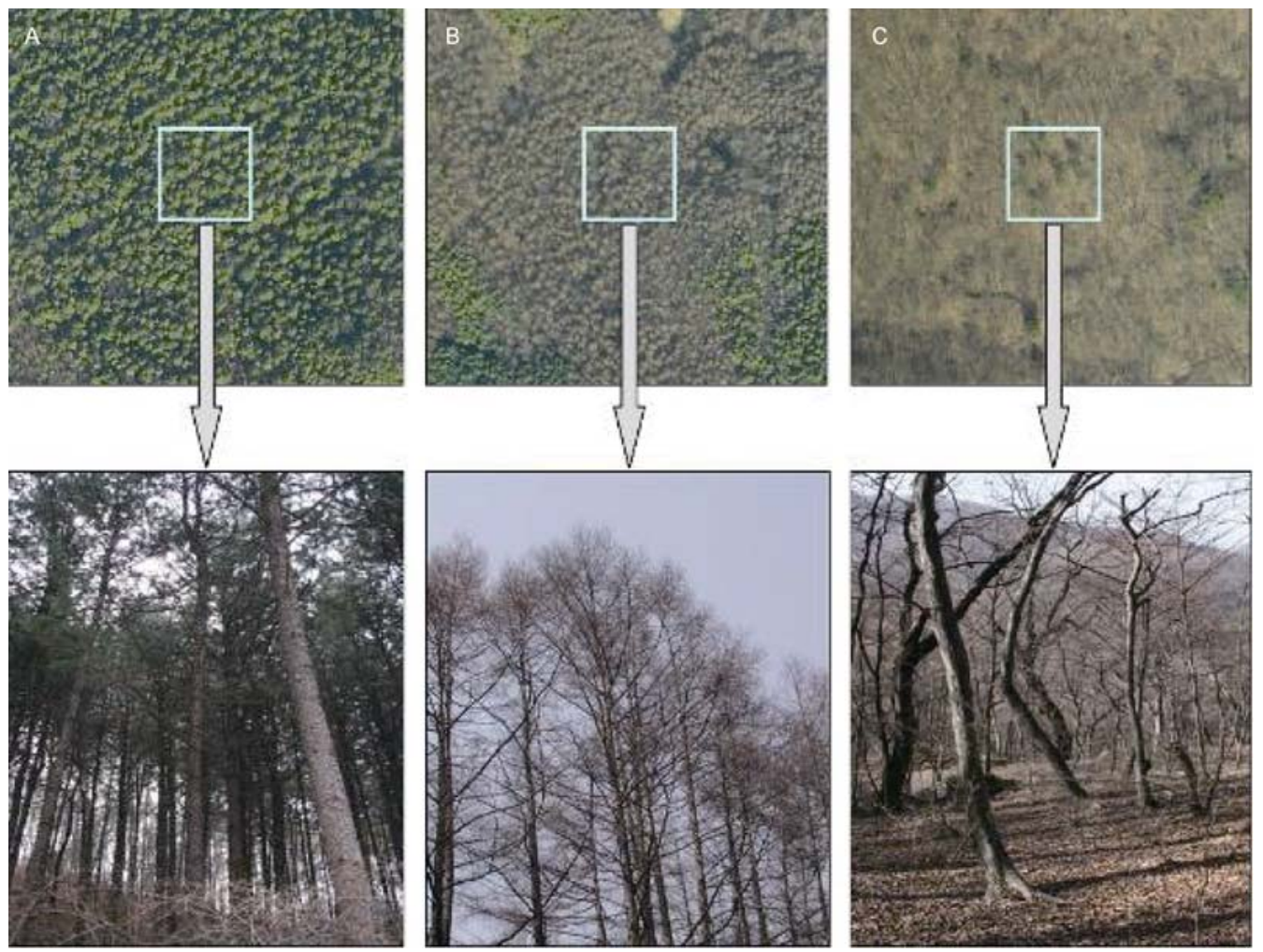

Figure 5 Structure of the stands surveyed according to the forest types (Korean Pines had dense leaves and Japanese Larches had abundant vertical branches. The Oaks had no leaves and fewer branches and therefore the surface of the forest area was exposed. By contrast the branches for the Japanese Larches showed abundant overlap). A, Korean Pine stand; B, Japanese Larch stand; C, Oaks stand.

est of the three forest types. This was due to the higher probability that LiDAR pulses were reflected from the high density of leaves in the canopy than from below the canopy. A larger number of LiDAR returns reflected from the canopy provides a better resulting description of the canopy and a greater accuracy of $\mathrm{PAI}_{\mathrm{e}}$ estimation. On the other hand, Japanese Larch $\left(R^{2}=0.58\right)$ and Oak $\left(R^{2}=0.51\right)$ showed lower correlations between estimates and actual ground data. This was attributed to the fact that neither of these forest types had leaves and that, particularly in the case of the Oaks, only a few branches were present. In the absence of leaves LiDAR pulses may be reflected only from the branches. The probability that LiDAR pulses would be reflected on bare branches is very low compared to branches with dense leaves present. This is because the size of the branch is smaller than the resolution across and along the 1 meter 
track of the laser beam. Therefore, here the LiDAR returns represent branches (woody components) without leaves. The correlation between the field-derived and LiDARderived $\mathrm{PAI}_{\mathrm{e}}$ of a bare-branched tree stand will be lower than for that of stands of trees with leaves. However, the correlation for the Japanese Larch stands was higher than that for the Oak stands. Hence, the probability that LiDAR pulses are reflected from the branches of Japanese Larches would be higher than that from the Oaks because the Japanese Larches have more abundant branches compared to the Oaks. Therefore, the woody component of Japanese Larches can be described adequately using LiDAR data.

\subsection{Accuracy assessment}

The $\mathrm{PAI}_{\mathrm{e}}$ estimations were evaluated by regression analysis using the field-derived $\mathrm{PAI}_{\mathrm{e}} \mathrm{s}$ for 45 plots $(15$ plots for each forest type) which were selected for such verification. The correlations for Korean Pines, Japanese Larches and Oaks were $0.82,0.64$ and 0.59 , respectively (Figure 6).

The estimated $\mathrm{PAI}_{\mathrm{e}} \mathrm{s}$ of Korean Pines had the highest $R^{2}$ of the three forest types. This was attributed to be a forest environment factor in that a greater number of LiDAR returns reflected from the densely leaved canopy can provide a better canopy description when compared to the fewer returns received from bare-leaved forest stands. During summer or early autumn, the accuracy of the regression function and its evaluation should therefore increase due to the higher probability that a larger number of laser pulses would be reflected from the leaves in the canopy for both the Japanese Larches and the Oaks at that time. The estimation of $\mathrm{PAI}_{\mathrm{e}} \mathrm{s}$ of bare-leaved trees, i.e., deciduous trees in late autumn and early spring, may be less valid and incomparable to $\mathrm{PAI}_{\mathrm{e}} \mathrm{S}$ of stands where leaves are present. Nevertheless, results of this study may be valuable because monitoring the change in the amount of leaves can provide information on seasonal changes in forests for rates of water interception, radiation extinction and water-carbon gas exchange [35].

\section{Discussion}

When the $\mathrm{PAI}_{\mathrm{e}}$ is calculated using LiDAR data, the $k_{L I D A R}$, derived from the incidence angle of the LiDAR pulse together with the leaf angle distribution, plays an important role in determining the accuracy of the method. In particular, the leaf angle distribution parameter should be representative of that of the particular forest type. In this study, the leaf angle distribution parameter was assumed to have a value of 1, suggesting an ellipsoidal angle distribution. In future studies, two variables, incidence angle and leaf angle distribution, should be further considered and refined to obtain a more accurate estimate of the $\mathrm{PAI}_{\mathrm{e}}$ using LiDAR data. It is also essential to consider other biological variables beyond that of the angle of leaf distribution. These include the vertical and horizontal distribution of leaves and branches, and the stand density. Other factors related to instrument settings also require consideration and statistical incorporation to improve the model. These include scan angle, footprint size and beam divergence. With the above considerations, progressively more accurate estimates of biophysical parameters in forested areas may become possible.

However, it is difficult to model the gap fraction bringing all the physical variables of the LiDAR system and all the biological variables of forested areas into consideration simultaneously. In this study a simpler attempt was made to test the utilization of LiDAR data for an effective evaluation of the plant area index using the variable of the ratio of ground to total returns. Even though the result might have been better if the other variables mentioned above had been considered more fully, nevertheless the number of ground and canopy returns in the forested area was related to the $\mathrm{PAI}_{\mathrm{e}}$. These other variables will be considered step by step in a future study.

The forest stands were classified into five classes. This included the understory layer class even in stands where there technically was no understory. In the case of mono-
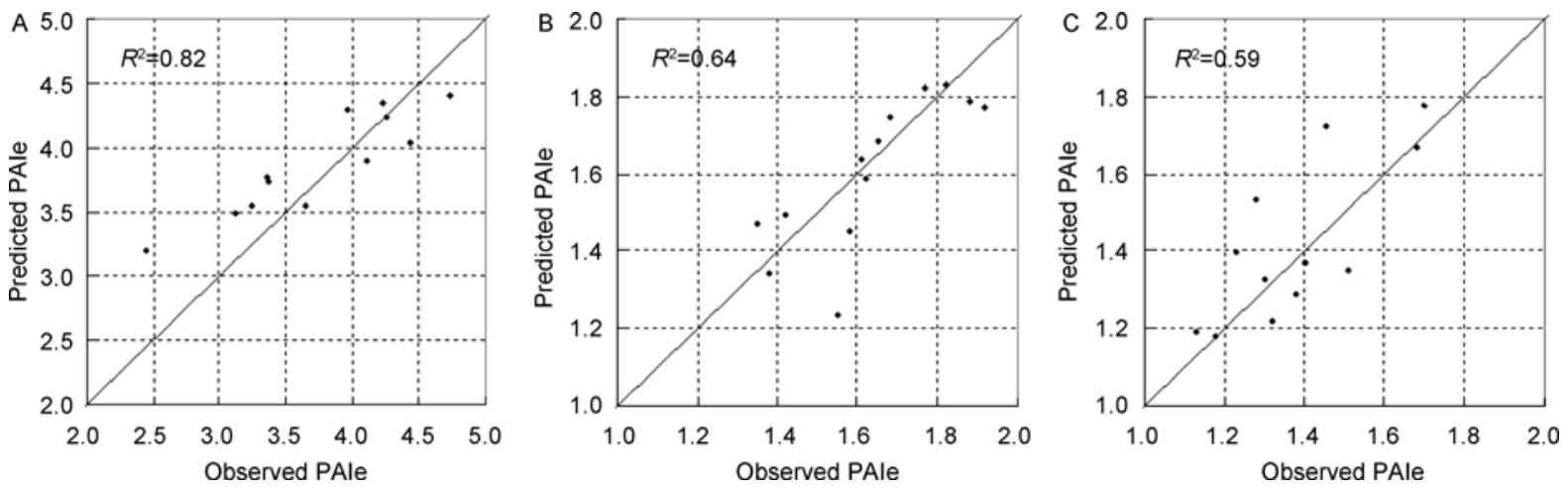

Figure 6 Assessment of the estimated $\mathrm{PAI}_{\mathrm{e}}$ according to the forest type. A, Korea Pine; B, Japanese Larch; C, Oaks. 
layer stands, such as for the Korean Pine stands, the under story in a plot was classified by $k$-means clustering as a description of the fallen leaf layer at ground level. However, the probability was that, in such cases, the understory class would be mistakenly classified into the crown base height class causing error in the calculation of the mean crown base height. Therefore, when the forest stand has a mono-layer, it becomes essential to perform $k$-mean clustering upon the four classes of ground, crown base height, half crown height and tree height class.

In this study the difference in accuracy of regression functions and their assessments can be attributed to whether or not the forest of the study area had leaves present. If all three forest types had abundant leaves, the differences of coefficients of determination for each forest type might also be attributed to the leaf properties, such as leaf physical form and structure. In general, laser pulses would probably have a greater chance of passing through needle or scalelike leaves than through broad leaves [36]. A pulse passing deeper into the crown would generate multiple returns for each echo. If foliage is distributed densely within the crown, such as for the Korean Pines, laser pulses would be primarily reflected from the canopy surface which is mostly composed of leaves. In contrast, laser pulses reflected from broadleaf stands have less chance of penetration into the canopy surface than those of needle leaf stands. Therefore, multiple returns passing through broad leaves might be generated in the mid canopy layer, rather than the canopy surface, as shown in Figure 7 [37].

However, this study was performed with some stands entirely devoid of leaves (Larch and Oak stands) with another stand having leaves present (the Pine stand). Therefore, the relative influence upon reflectance by leaf properties could not be evaluated. Therefore, the main factor affecting the variation of accuracies was determined to be simply the presence of absence of leaves on branches. In future LiDAR studies, the difference of reflectance between broad- and needle-leaves should be evaluated using data acquired in late spring or summer where leaves of all trees will be present.

\section{Conclusion}

The $\mathrm{PAI}_{\mathrm{e}}$ was estimated using the characteristics of laser interception by the canopies of three forest types: Korean Pine, Japanese Larch and Oak. The coefficients of determination between the observed and predicted $\mathrm{PAI}_{\mathrm{e}}$ for these three types were $0.82,0.64$ and 0.59 , respectively. The relatively low prediction ability for the latter two species was attributed to the fact that these two species were devoid of leaves, in contrast to the former species which had abundant leaves. The better prediction for the Japanese Larches as compared to the Oaks was likely to be because the Japanese Larch trees had many branches while the Oaks had very few. This corresponded to the probability of how many branch reflected LiDAR pulses would be likely returned for each of these species. In conclusion, $\mathrm{PAI}_{\mathrm{e}}$ can be effectively estimated using airborne LiDAR data. The accuracies of LiDAR-derived $\mathrm{CBH}$ and $\mathrm{PAI}_{\mathrm{e}}$ can be acceptable, especially when considering the time and effort required for data collection in the field using manual measurements. Better accuracy would be expected if the study would be performed in late spring when shoots and leaves begin to appear. Another future investigation is planned to estimate the $\mathrm{PAI}_{e}$ in another deciduous forest type and also to analyze seasonal differences in the $\mathrm{PAI}_{\mathrm{e}}$ using comparison of LiDAR data acquired during the leaf-on and leaf-off seasons.
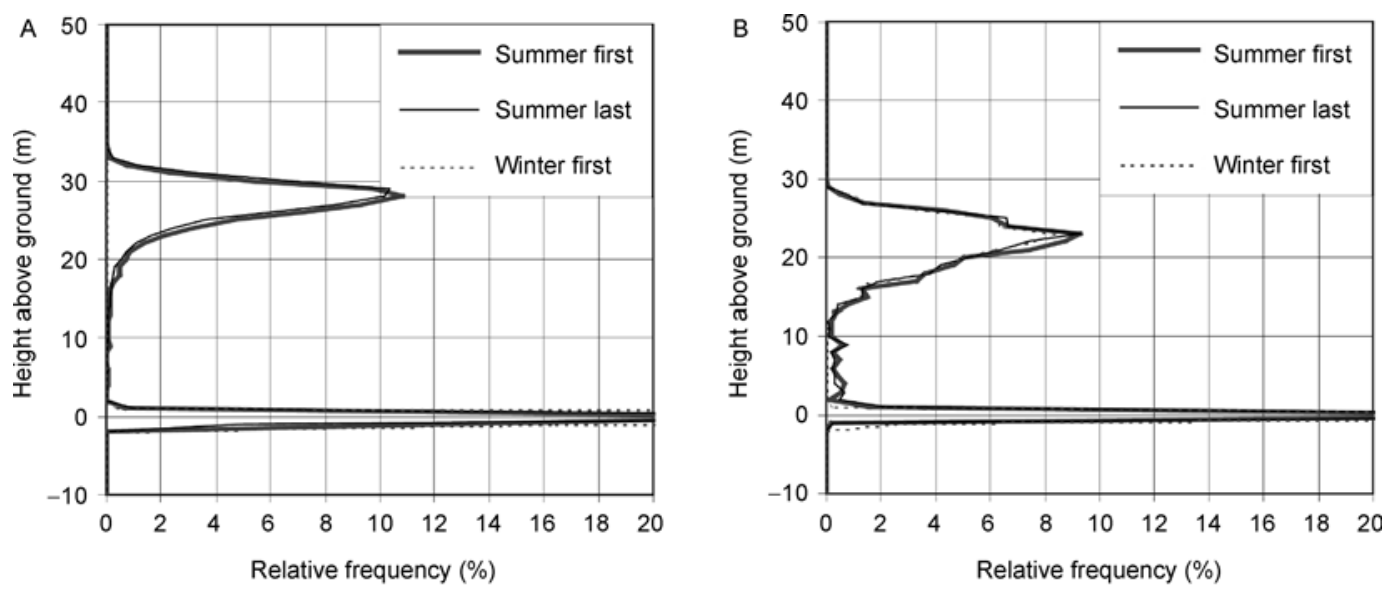

Figure 7 Relative LiDAR data frequency according to stand height in coniferous and deciduous stands [37]. The relative frequency reflected from the canopy surface is higher from the coniferous stand than from the deciduous stand. Therefore, the vertical length of the coniferous canopy described by LiDAR data is shorter than that of the deciduous canopy. A, Coniferous stand; B, deciduous stand. 
This research was supported by a grant from the High Tech Urban Development Program funded by Ministry of Land, Transportation and Maritime Affairs of Korean government (Grant No. 07High Tech A01), as well as by a research grant from the Korea Science and Engineering Foundation (KOSEF) (Grant No. A307-K001).

1 Bréda N J J. Ground-based measurements of leaf area index: a review of methods, instruments and current controversies. J Exp Bot, 2003, 54: $2403-2417$

2 Bonan G B. Importance of leaf area index and forest type when estimating photosynthesis in boreal forests. Remote Sens Environ, 1993, 43: $303-314$

3 Finney M. Farsite: Fire area simulator-model. Development and evaluation. Research Paper RMRS-RP-4. USDA Forest Service, 1998

4 Pellant M, Shaver P, Pyke D A, et al. Interpreting indicators of rangeland health, ver 3, Technical Reference 1734-6. USDI, BLM, Natural Science and Technology Center, Denver, Colorado, 2000

5 Whisenant S G. Repairing Damaged Wildlands: A Process-oriented, Landscape-scale Approach. London: Cambridge University Press, 1999

6 Jonckheere I, Fleck S, Nackaerts K, et al. Review of methods for in situ leaf area index determination: Part i. theories, sensors and hemispherical photography. Agric For Meteorol, 2004, 121: 19-35

7 Watson D J. Comparative physiological studies in the growth of field crops: I. Variation in net assimilation rate and leaf area between species and varieties, and within and between years. Anal Bot, 1947, 11: $41-76$

8 Schulze E D, Beck E, Müller-Hohenstein K, eds. Plant Ecology. Berlin: Springer, 2005

9 Myneni R, Ramakrishna R, Nemani R, et al. Estimation of global leaf area index and absorbed par using radiative transfer models. IEEE Trans Geosci Remote Sens, 1997, 35: 1380-1393

10 Cohen W B, Maiersperger T K, Gower S T, et al. An improved strategy for regression of biophysical variables and landsat etm + data. Remote Sens Environ, 2003, 84: 561-571

11 Koetz B, Schaepman M, Morsdorf F, et al. Radiative transfer modeling within a heterogeneous canopy for estimation of forest fire fuel properties. Remote Sens Environ, 2004, 92: 332-344

12 Price J C, Bausch W C. Leaf area index estimation from visible and near-infrared reflectance data. Remote Sens Environ, 2002, 52: 5565

13 Fernandes R, Miller J R, Hu B. A multi-scale approach to mapping effective leaf area index in Boreal Picea mariana stands using high spatial resolution CASI imager. Int J Remote Sens, 2002, 18: 35473568

14 Chen X, Vierling L, Rowell E, et al. Using lidar and effective LAI data to evaluate IKONOS and Landsat 7 ETM+ vegetation cover estimates in a ponderosa pine forest. Remote Sens Environ, 2004, 91: 14-26

15 Macfarlane C, Hoffman M, Eamus D, et al. Estimation of leaf area index in eucalypt forest using digital photography. Agric For Meteorol, 2007, 143: 176-188

16 Kwak D A, Lee W K, Lee J H, et al. Detection of individual trees and estimation of tree height using LiDAR data. J For Res, 2007, 12: 425-434

17 Holmgren J, Nilsson M, Olsson H. Estimation of tree height and stem volume on plots using airborne laser scanning. Forest Sci, 2003, 49: 419-428

18 Morsdorf F, Kötz B, Meier E, et al. Estimation LAI and fractional cover from small footprint airborne laser scanning data based on gap fraction. Remote Sens Environ, 2006, 104: 50-61

19 Riaño D, Valladares F, Condés S. Estimation of leaf area index and covered ground from airborne laser scanner (Lidar) in two contrasting forests. Agric For Meteorol, 2004, 124: 269-257

20 Weiss M, Baret F, Smith G J, et al. Review of methods for in situ leaf area index (LAI) determination: Part II. Estimation of LAI, errors and sampling. Agric For Meteorol, 2004, 121: 37-53

21 Lovell J, Jupp D, Culvenor D. Using airborne and ground-based ranging lidar to measure canopy structure in Australian forests. Can J Remote Sens, 2003, 29: 607-622

22 Koetz B, Morsdorf F, Sun G. Inversion of a lidar waveform model for forest biophysical parameter estimation. IEEE Geosci Remote Sens, 2006, 3: 49-53

23 Morsdorf F, Kötz B, Meier E. The potential of discrete return, small footprint airborne laser scanning data for vegetation density estimation. In: Proceedings of ISPRS WG III/3, III/4, V/3 Workshop Laser scanning 2005. Enschede, the Netherlands, September 12-14, 2005. 198-203

24 Van Aardt J A N. An object-oriented approach to forest volume- and above-ground biomass-by-type modeling using small-footprint lidar data for segmentation, estimation, and classification. Dissertation for Doctoral Degree, Virginia: Virginia Polytechnic Institute and State University, 2004

25 Pocewicz A L, Gessler P, Robinson A P. The relationship between effective plant area index and Landsat spectral response across elevation, solar insolation, and spatial scales in a northern Idaho forest. Can J For Res, 2004, 34: 465-480

26 Chen J M. Optically-based methods for measuring seasonal variation of leaf area index in boreal conifer stands. Agric For Meteorol, 1996, 80: $135-163$

27 Wohlfahrt G, Sapinsky S, Tappeiner U, et al. Estimation of plant area index of grasslands from measurements of canopy radiation profiles. Agric For Meteorol, 2001, 109: 1-12

28 Chen, J M, Cihlar J. Retrieving leaf area index of boreal conifer forests using Landsat TM images. Remote Sens Environ, 1996, 55: $153-162$

29 Lee J K, Hwang C S, Jung S H. Analysis of accuracy for the control points using the GPS continuous stations (In Korean with English abstract). KSCE J Civ Eng, 2003, 23: 401-409

30 Gower S T, Kucharik C J, Norman J M. Direct and indirect estimation of leaf area index, fAPAR, and net primary production of terrestrial ecosystems. Remote Sens Environ, 1999, 70: 29-51

31 Campbell G S. Extinction coefficients for radiation in plant canopies calculated using an ellipsoidal inclination angle distribution. Agric For Meteorol, 1986, 36: 317-321

32 Kozlowski T T, Kramer P J, Pallardy S G. The Physiological Ecology of Woody Plants. San Diego: Academic Press, 1991

33 MATLAB. Help Document In Program. Mathwork: United States of America, 2006

34 Barilotti A, Turco S, Alberti G. LAI determination in forestry ecosystem by lidar data analysis. In: Proceedings of Workshop on 3D Remote Sensing in Forestry. Vienna, Austria, February 14-15, 2006. 248-252

35 Kim S H, Park J H, Woo C S, et al. Analysis of temporal variability of MODIS Leaf Area Index (LAI) product over temperate forest in Korea. In: Proceedings of IEEE International Geoscience and Remote Sensing Symposium. Seoul, Korea, July 25-29, 2005. 4343-4346

36 Kim S Y. Individual tree species identification using LiDAR-derived crown structure and intensity data. Dissertation for Doctoral Degree, Washington: University of Washington, 2007. 58-60

37 Rieger W, Eckmüllner O, Müllner H. Laser-Scanning for the derivation of forest stand parameters. In: Proceedings of the ISPRS Commission III, WG 5 and WG 2 Workshop Mapping Surface Structure and Topography by Airborne and Spaceborne Lasers. La Jolla, USA, November 9-11, 1999, 193-200 